\title{
ОЦЕНКА И СРАВНИТЕЛЬНЫЙ АНАЛИЗ СОСТОЯНИЯ БУККАЛЬНОГО ЭПИТЕЛИЯ И СТОМАТОЛОГИЧЕСКОГО ЗДОРОВЬЯ У ЛИЦ, УВЛЕКАЮЩИХСЯ КУРЕНИЕМ ТАБАЧНЫХ И ЭЛЕКТРОННЫХ СИГАРЕТ
}

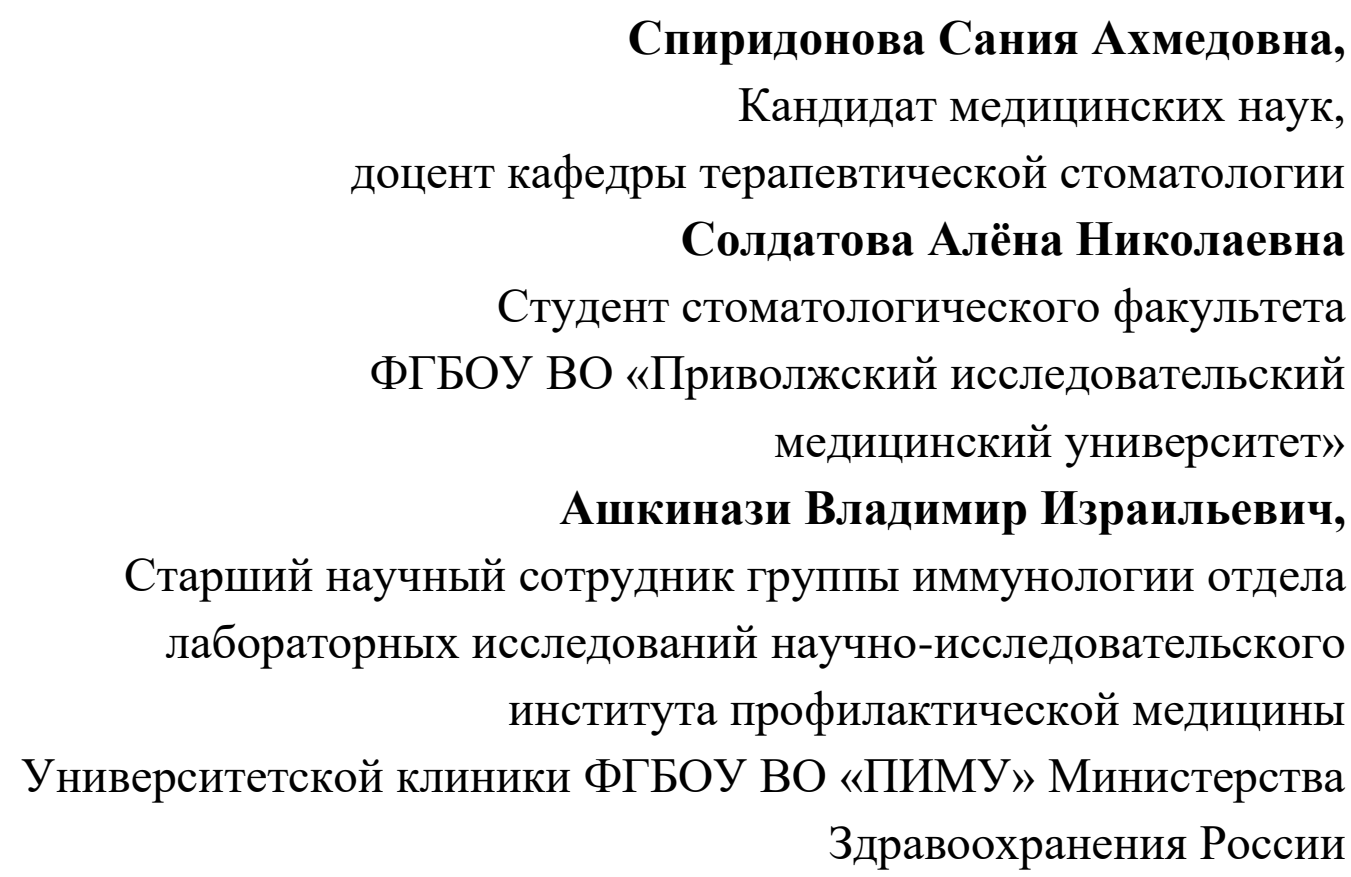

Аннотация: На основании данных комплексного обследования состояния полости рта у 21 респондента в возрасте от 21 до 26 лет был произведен анализ полученных результатов и сделаны выводы о влиянии различных видов курения на состояние стоматологического здоровья. Респонденты изначально были разделены на 3 группы по 7 человек: некурящие, курящие электронные сигареты, курящие табачные сигареты. На момент обследования все пациенты не имели хронических и инфекционных заболеваний, прием лекарственных препаратов на момент осмотра был исключен. Комплексная оценка состояния полости рта включала в себя: мониторинг состояния буккального эпителия, оценку стоматологических индексов (индекса Грина-Вермиллиона (Green, Vermillion, 1964), индекса кровоточивости по Мюллеману (в модификации Коуэла) и папиллярномаргинально-альвеолярного (РМА) индекса), рh-метрию ротовой жидкости, определение количества содержания кальция в ротовой жидкости.

В результате проведенного исследования было выявлено, что курение и табачных и электронных сигарет повышает риск развития различных патологических изменений в эпителии полости рта, нарушая его нормальное 
ороговение вне зависимости от средств курения. Стоит уточнить, что снижение реактивности клеточных элементов влечет за собой угнетение защитных свойств эпителиоцитов слизистой оболочки. Значения индексов ГринаВермиллиона (Green, Vermillion, 1964), индекса кровоточивости по Мюллеману (в модификации Коуэла) и папиллярно-маргинально-альвеолярного (РМА) индекса также говорят об ухудшении гигиены полости рта и состояния пародонта у курящих табачные и электронные сигареты респондентов. Более пагубным видом курения является курение табака, о чем говорят повышенные показатели $\mathrm{pH}=8,098 \pm 0,001$ и концентрации ионов кальция в ротовой жидкости $2,7 \pm 0,001$ ммоль/л после курения. Полученные данные увеличивают фонд знаний о влиянии различных видов курения на здоровье полости рта человека и могут быть использованы, как в мета-аналитических исследованиях, так и в информационной борьбе с курением.

Ключевые слова: курение, здоровье полости рта, буккальный эпителий, ph-метрия ротовой жидкости, количественное определение ионов кальция в ротовой жидкости, электронные сигареты, табачные сигареты, индекс ГринаВермиллиона, индекс кровоточивости по Мюллеману, папиллярномаргинально-альвеолярный индекс.

\title{
ASSESSMENT AND COMPARATIVE ANALYSIS OF THE STATE OF THE BUCCALE EPITHELIUM AND ORAL CAVITY HEALTH IN PERSONS HAVING TO SMOK TOBACCO AND ELECTRONIC CIGARETTES
}

\author{
Spiridonova Saniya Akhmedovna \\ Ashkinazi Vladimir Izrailevich \\ Soldatova Alyona Nikolaevna
}

\begin{abstract}
Based on the data of a comprehensive oral health examination in 21 respondents aged 21 to 26 years, the results were analyzed and conclusions were drawn about the effect of different types of smoking on dental health. The respondents were initially divided into 3 groups of 7: nonsmokers, e-cigarette smokers, and tobacco cigarette smokers. All patients were free of chronic and infectious diseases at the time of examination, taking medications at the time of examination was excluded. Comprehensive assessment of the state of the oral cavity included: monitoring the state of buccal epithelium, assessment of dental indices (Green-Vermillion index (Green, Vermillion, 1964), Muellman bleeding index


(modified by Cowell) and papillary-marginal-alveolar (PMA) index), ph-metry, determination of calcium content in oral fluid.

The study revealed that smoking both tobacco and electronic cigarettes increases the risk of developing various pathological changes in the oral epithelium, disrupting its normal keratinization regardless of the means of smoking. It is worth specifying that reduction of reactivity of cellular elements entails inhibition of protective properties of mucosal epitheliocytes. Values of the Green-Vermillion index (Green, Vermillion, 1964), the Muellman bleeding index (modified by Cowell) and the papillary-marginal-alveolar (PMA) index also speak about the worsening of oral hygiene and periodontal condition in respondents who smoke tobacco and electronic cigarettes. Tobacco smoking is more detrimental, as indicated by elevated $\mathrm{pH}=8.098 \pm 0.001$ and oral calcium ion concentrations of $2.7 \pm 0.001 \mathrm{mmol} / \mathrm{L}$ after smoking. The data obtained increase the fund of knowledge about the effect of different types of smoking on human oral health and can be used both in metaanalytical studies and in informational anti-smoking.

Keywords: smoking, oral health, buccal epithelium, oral fluid ph-metry, quantitative determination of calcium ions in the oral fluid, electronic cigarettes, tobacco cigarettes, Green-Vermillion index, Müllemann, Cowell's bleeding index, papillary-marginal-alveolar index.

Введение: Высочайший уровень распространенности курения является ведущей медико-социальной проблемой, которую на сегодняшний день решает мировое сообщество. В 2020 году Всемирная организация здравоохранения назвала табачную эпидемию одной из наиболее угрожающих для человечества: около 1,3 миллиарда людей курило табак, ежегодно его потребление влекло гибель более 8 миллионов человек. Табачная зависимость включена в Международную статистическую классификацию болезней. Курение пагубно влияет на состояние всех систем организма, увеличивает риск возникновения онкологических заболеваний, приводит к хроническому стрессу, вызванному зависимостью, тем самым резко снижая уровень жизни человека $[2$, c.310].

Помимо табачных сигарет около 10 лет назад на мировом рынке стали активно реализовываться электронные сигареты. По приблизительным оценкам на 2020 год, около 20,8 миллионов человек в мире курят именно их. Производители данной продукции позиционируют ее как альтернативный, более безвредный способ курения [3, с.122]. Тем не менее на текущий момент 
воздействие данного вида курения на здоровье продолжает активно изучаться всемирным научным сообществом.

Все вышесказанное обуславливает актуальность исследования влияния различных видов курения на стоматологическое здоровье населения. Комплексная оценка состояния полости рта может быть произведена на основе мониторинга состояния буккального эпителия, оценки стоматологических индексов (индекса Грина-Вермиллиона (Green, Vermillion, 1964), индекса кровоточивости по Мюллеману (в модификации Коуэла) и папиллярномаргинально-альвеолярного (РМА) индекса), рh-метрии ротовой жидкости, а также определения количества содержания кальция в ротовой жидкости. Проанализировав данные параметры у респондентов, курящих табачные и электронные сигареты, мы можем сравнить и оценить влияние данных видов курения на стоматологический статус испытуемых.

Цель исследования: Изучить и сравнить влияние курения табачных и электронных сигарет на буккальный эпителий слизистой оболочки полости рта и стоматологическое здоровье испытуемых.

Материал и методы: В исследовании приняли участие 21 человек: из них 7 человек - курят табачные сигареты, 7 человек - курят электронные сигареты, 7 человек - не курят. Возраст пациентов составил 21士1,4 года, стаж курения составлял не более 5 лет. На момент обследования все пациенты не имели хронических и инфекционных заболеваний, прием лекарственных препаратов на момент осмотра был исключен.

Обследуемым проводилось комплексное обследование, состоящее из:

1) Осмотра полости рта и определения индекса Грина-Вермиллиона (Green, Vermillion, 1964), индекса кровоточивости по Мюллеману (в модификации Коуэла) и папиллярно-маргинально-альвеолярный (РМА) индекса.

2) Исследования буккального эпителия: у всех пациентов выполнялся забор биоматериала со слизистой оболочки щек при помощи металлической ложки, забирали материал утром, натощак. Далее материал разбавлялся физиологическим раствором, собирался в стерильные пробирки и отправлялся в лабораторию для проведения исследования. Проводилось вычисление индекса дифференцировки (ИДиф) и индекса ороговения (ИО) эпителиоцитов.

3) Количественного определения ионов кальция в ротовой жидкости с помощью ион-селективного электрода. Ионизированный кальций в ротовой жидкости составляет около 55\% от общего количества кальция, именно он является наиболее информативным с клинической точки зрения и позволяет 328 
судить об активности процессов де- и реминерализации. Нормальной является концентрация ионизированного кальция в слюне от 0,64 до 1,84 ммоль/л.

4) Количественного определения $\mathrm{pH}$ ротовой жидкости с помощью прибора $\mathrm{pH}$-метра (иономера). Слюна в составе ротовой жидкости обладает ярко выраженными бактерицидными и бактериостатическими свойствами благодаря ряду ферментов и биологически активных веществ, входящих в ее состав. Активность данных веществ наиболее высока при оптимальном значении $\mathrm{pH}$ 5,6-7,9. Следовательно, состояние слизистой оболочки полости рта, пародонта, а также здоровье зубов будут зависеть от этого показателя. Ротовая жидкость забиралась натощак до и после курения табачных или электронных сигарет испытуемыми.

Полученные данные оценивали, используя критерий Стьюдента, и с помощью программы «Biostat».

Результаты исследования. Были обследованы 11 мужчин (52\%) и 10 женщины (48\%) в возрасте от 18 до 26 лет.

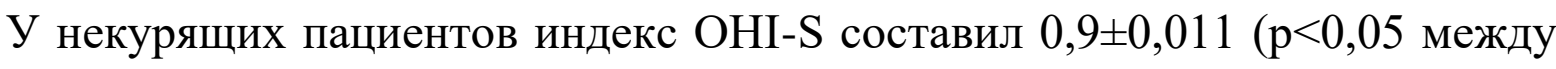
группами), индекс кровоточивости по Мюллеману - 0,6 $\pm 0,01$ ( $<00,05$ между группами), индекс РМА - 1,32 $\pm 0,03 \%$ ( $<0,05$ между группами). У пациентов курящих табачные сигареты значения составили: индекс OHI-S составил $0,87 \pm 0,012$ ( $<<0,05$ между группами), индекс кровоточивости по Мюллеману $0,69 \pm 0,01$ ( $<<0,05$ между группами), индекс PMA - 1,32 $\pm 0,03 \%$ ( $<0,05$ между группами), а у респондентов, курящих электронные сигареты: индекс OHI-S составил $1,3 \pm 0,012$ ( $<00,05$ между группами), индекс кровоточивости по

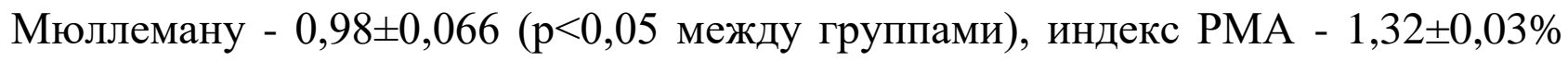
( $<<0,05$ между группами).

При изучении индекса дифференцировки эпителиоцитов у некурящих не было выявлено отклонений от нормы, что соответствовало - Идиф $391 \pm 2,8$ усл.ед. У обследуемых курящих, использующих табачные сигареты отмечалось повышение ИДиф $435 \pm 3,2$ усл.ед., что можно связать с токсическим воздействием табака на слизистую оболочку полости рта; в отношении пациентов, употребляющих электронные сигареты, отмечалось незначительное повышение ИДиф 420 2.9 усл.ед., что объясняется длительностью воздействия высоких температур на слизистую полости рта. Так же выявлено значительное повышение индекса ороговения (ИО) у пациентов, курящих табачные сигареты, что сопровождалось повышением количества патологических митозов в эпителиоцитах, также, как и у пациентов, курящих электронные сигареты -

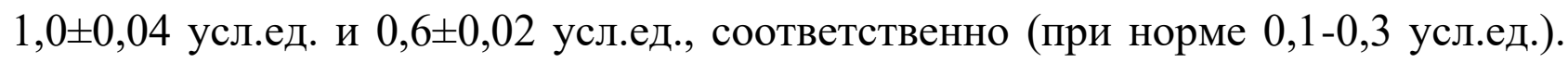


Увеличение показателей ИДиф и ИО связано с увеличением количества митозов в эпителиоцитах. У курящих пациентов отмечается развитие явлений гиперкератоза слизистой оболочки полости рта в следствии токсического влияния табака и повышения 5-ой стадии дифференцировки эпителиоцитов, что свидетельствует о неспособности клеточных структур к омоложению.

При анализе образцов ротовой жидкости респондентов было выявлено, что наиболее высокая концентрация ионизированного кальция в слюне

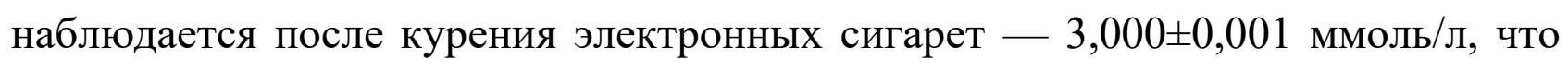
превышает верхнюю границу нормы в 1,6 раза и свидетельствует об активно идущем процессе деминерализации. У молодых людей, употребляющих табачные сигареты, концентрация кальция в слюне увеличилась на 53,9 \% соответственно, что, безусловно, говорит о пагубном влиянии данных видов курения.

Показатели $\mathrm{pH}$ ротовой жидкости в группе некурящих испытуемых составили 7,233 $\pm 0,002$. У всех исследуемых сразу после курения отмечалось резкое увеличение $\mathrm{pH}$ слюны, которая у группы курящих табачные сигареты доходила до 8,098 $\pm 0,001$. При повышении $\mathrm{pH}$ слюны происходит быстрое депротонирование ионов дигидрофосфата, образованные ионы $\mathrm{PO}^{-3}$, взаимодействуя с кальцием, формируют труднорастворимые соли ортофосфата кальция зубного камня [1, с.398].

Заключение: Таким образом, проведя комплексную оценку стоматологического статуса некурящих и курящих табачные и электронные сигареты респондентов можно сделать следующие выводы:

1) Курение и табачных и электронных сигарет повышает риск развития различных патологических изменений в эпителии полости рта, нарушая его нормальное ороговение вне зависимости от средств курения. Стоит уточнить, что снижение реактивности клеточных элементов влечет за собой угнетение защитных свойств эпителиоцитов слизистой оболочки.

2) Значения индексов Грина-Вермиллиона (Green, Vermillion, 1964), индекса кровоточивости по Мюллеману (в модификации Коуэла) и папиллярно-маргинально-альвеолярного (РМА) индекса также говорят об ухудшении гигиены полости рта и состояния пародонта у курящих табачные и электронные сигареты респондентов.

3) Более пагубным видом курения является курение табака, о чем говорят повышенные показатели $\mathrm{pH}=8,098 \pm 0,001$ и концентрации ионов кальция в ротовой жидкости $2,7 \pm 0,001$ ммоль/л после курения. 


\section{Список литературы}

1. Биохимия. Учебник. Под ред. Северина Е.С. 2 изд., испр. М.: ГЭОТАРМЕД - 2004 - С. 398-408.

2. Леонтьев В.К., Пахомов Г.Н. Профилактика стоматологических заболеваний. М.- 2006 -С. 310.

3. Антоново Н. С., Сахарова Г. М., Донитова В. В. Электронные сигареты: оценка безопасности и рисков для здоровья / Антонов Н. С., Сахарова Г.М., Донитова В.В. - СПб.: Пульмонология, 2014, N 3.- С. 122-127.

(C) С.А. Спиридонова, А.Н. Солдатова, В.И. Ашкинази, 2022 